\title{
Genome sequencing and molecular characterisation of Staphylococcus aureus ST772-MRSA-V, "Bengal Bay Clone"
}

\author{
Stefan Monecke ${ }^{1,2^{*}}$, Vico Baier ${ }^{2}$, Geoffrey W Coombs ${ }^{3,4}$, Peter Slickers ${ }^{2}$, Albrecht Ziegler ${ }^{2}$ and Ralf Ehricht ${ }^{2}$
}

\begin{abstract}
Background: The PVL-positive ST772-MRSA-V is an emerging community-associated (CA-) MRSA clone that has been named Bengal Bay Clone since most patients have epidemiological connections to the Indian subcontinent. It is found increasingly common in other areas of the world.

Methods: One isolate of ST772-MRSA-V was sequenced using the Illumina Genome Analyzer System. After initial assembling the multiple sequence contigs were analysed using different in-house annotation scripts. Results were compared to microarray hybridisation results of clinical isolates of ST772-MRSA-V, of related strains and to another ST772-MRSA-V genome sequence.

Results: According to MLST e-burst analysis, ST772-MRSA-V belongs to Clonal Complex (CC)1, differing from ST1 only in one MLST allele (pta-22). However, there are several additional differences including agr alleles (group II rather than III), capsule type (5 rather than 8), the presence of the egc enterotoxin gene cluster and of the enterotoxin homologue ORF CM14 as well as the absence of the enterotoxin $\mathrm{H}$ gene seh. Enterotoxin genes sec and sel are present. ST772-MRSA-V harbours the genes encoding enterotoxin A (sea) and PVL (IukS/F-PV). Both are located on the same prophage.
\end{abstract}

Conclusions: ST772-MRSA-V may have emerged from the same lineage as globally spread CC1 and CC5 strains. It has acquired a variety of virulence factors, and for a CA-MRSA strain it has an unusually high number of genes associated with antibiotic resistance.

\section{Background}

In recent years the epidemiology of methicillin-resistant Staphylococcus aureus (MRSA) has changed with the emergence of community associated MRSA (CA-MRSA) strains. Unlike the original healthcare associated MRSA strains, CA-MRSA strains are no longer restricted to the hospital setting and can persist in and be transmitted by healthy individuals in the community. Some of these strains exhibit an enhanced virulence due to the carriage of a number of virulence genes, including the Panton Valentine leukocidin (PVL) $l u k F-P V$ and $l u k S$ $P V$ determinants. PVL is a phage-borne, bi-component

\footnotetext{
* Correspondence: monecke@rocketmail.com

'Institute for Medical Microbiology and Hygiene, Technical University of Dresden, Dresden, Germany

${ }^{2}$ Alere Technologies GmbH, Jena, Germany

Full list of author information is available at the end of the article
}

toxin [1] associated with chronic/recurrent skin and soft tissue infections and with necrotising pneumonia and fasciitis [2].

ST772-MRSA-V, colloquially known as the Bengal Bay Clone [3], is a multiresistant PVL-positive CA-MRSA initially isolated in India in 2004/2005 [4]. Transmission of Bengal Bay MRSA has subsequently occurred in several countries including England [3], Ireland [5], Germany (H.J. Linde, Regensburg, Germany, pers. communication; [6]), Norway (H. Aamot, pers. communication), Italy [7,8], Abu Dhabi [6,9], Saudi Arabia [10], Hong Kong [6], Malaysia [11], Australia [12] and New Zealand [13]. Many patients had a travel history or family background suggesting an infection in India, Pakistan or Bangladesh ([3,5,12]; H.J. Linde, Regensburg, Germany, pers. communication; author's unpublished observations), where this strain appears to be increasingly common $[14,15]$. 
In order to identify possible factors promoting its recent emergence and spread we have sequenced the ST772-MRSA-V genome.

\section{Methods \\ Strains}

One isolate of ST772-MRSA-V (07-17048) was selected for next generation genome sequencing. It was isolated from an Indian healthcare worker in Western Australia as part of standard patient care in 2007 and submitted to the Australian Collaborating Centre for Enterococcus and Staphylococcus Species for typing. Thirteen related isolates that were previously submitted for typing purposes to the participating institutions were selected. Their microarray hybridisation profiles where compared to isolate 07-17048 especially with regard to genes associated with resistance or virulence (Table 1, Additional file 1).

\section{Methods}

High-throughput de novo sequencing was undertaken commercially by Geneservice Source BioScience plc (Nottingham, United Kingdom) using the Illumina Genome Analyzer System (Illumina Hiseq 2000 platform, Illumina, Essex, United Kingdom). The average genome coverage was $c a$. 105. The reads were assembled to contigs using the Velvet de novo genome assembler (vers.1.0.15; Illumina). The project was registered with the NCBI BioProject database under the provisional accession number PRJNA207032 and has been deposited at $\mathrm{DDBJ} / \mathrm{EMBL} / \mathrm{GenBank}$ under the accession number AZBT00000000.

Microarray procedures have been previously described in detail [6].

\section{Analysis}

Analysis was performed using automated scripts for full text comparison and BLAST analysis and an in-house database of known, annotated and previously identified $S$. aureus genomes, genes and gene fragments to the query sequence. This allows determination of identity, clonal parentage and (given the constant order of core genomic genes in $S$. aureus) position within the genome of each contig (Additional file 2). In parallel, iterated BLAST searches were used for analysis of individual contigs in order to confirm results (http://blast.ncbi.nlm. nih.gov/Blast.cgi; [20]).

\section{Results and discussion}

In terms of microarray hybridisation patterns, the sequenced strain represents the typical and most common variant of the Bengal Bay Clone (Table 1 and Additional file 1). The isolate $07-17048$ was found to belong to the multilocus sequence type (MLST) ST772 (1-1-1-1-22-1-1), spa type t3387 (RIDOM nomenclature, [21], repeat sequence 26-16-21-17-34-33-34) and dru type dt10ao (5a4a-0-2d-5b-3a-2 g-3b-4e-3e). According to MLST e-burst analysis, ST772 is considered to belong to CC 1 as it differs from ST1 only in one MLST allele (pta-22). However, because of several differences, as shown below, its inclusion into $\mathrm{CC} 1$ needs to be re-assessed.

A total of 340 contigs were obtained after initial assembling. Seventy contigs consisting of 2,741,418 base pairs have been analysed (Additional file 2). The overall G/C content was 33\%. 1,946 protein coding sequences have been identified (Additional file 3). 1,234 protein coding sequences were completely identical to previously identified genes from other $S$. aureus strains. A total number of 416, 239 and 101 protein coding sequences were completely identical to alleles from CC1 genome sequences (from MSSA476, GenBank accession number BX571857 and MW2-USA400, BA000033), CC5 genome sequences (from Mu50, BA000017; ED98, CP001781 and N315, BA000018) and CC8 genome sequences (from COL, CP000046; Newman, AP009351 and NCTC8325, CP000253) respectively. Three-hundred eighty-three genes were identical only to another ST772-MRSA-V sequence (strain 118, whole genome shotgun project AJGE00000000, [22]). Based on identities to previously published gene sequences, ST772-MRSA-V is most closely related to CC1 and $\mathrm{CC} 5$. Genes of $\mathrm{CC} 1$ and $\mathrm{CC} 5$ backgrounds are scattered across the genome, and no evidence for a distinct part of the genome being affected by a genomic replacement (as observed in, for instance, ST239; [23]) can be found. Theoretically, this may be attributed to a high number of recombination events involving CC1 and CC5 strains, or may indicate a common ancestry for both lineages and subsequent accumulation of random mutations in genes that are essentially orthologs in CC1, CC5 and ST772. The question whether the presence of different capsule types and agr groups in otherwise closely related strains (such as ST1 and ST772) can be attributed to recombination or to convergent evolution justifies further study.

Several fundamental differences in the ST772 and CC1 core genomic markers have already been identified by microarray DNA [6] and have been confirmed by sequencing. These differences include $a g r$ alleles (group II rather than III), the capsule type (5 rather than 8 ) and the presence of different allelic variants of $h l b$, sslo1/ set6, $b b p, c l f B, f n b B, s d r C, s d r D, v w b$ and $h s d S$. The egc enterotoxin gene cluster, Q7A4X2 (a hypothetical protein localised close to egc), the metallothiol transferase gene fos $B$ and the enterotoxin homologue ORF CM14 are present in ST772 but absent from other CC1 strains. The genes seh (encoding enterotoxin $\mathrm{H}$ ), lukD/E (a leukocidin homologue), splA/B/F (serine proteases), ssl11/set2, ssl06/set21 (superantigen-like proteins), and Q2FXC0 
Table 1 Overview on typing and microarray hybridisation data for CC1 reference strains (nr. 1 and 2 ), CC5 reference strains (nr. 3 and 4 ), the strain described herein (nr. 5), other Bengal Bay isolates (nr. 6 to 14) and other, related strains (nr. 15 to 18)

\begin{tabular}{|c|c|c|c|c|c|c|c|c|c|c|c|c|c|c|c|c|c|c|}
\hline Nr. & Isolate & Origin & Reference & $\begin{array}{l}\text { RIDOM } \\
\text { spa }\end{array}$ & MLST & agr & $\begin{array}{l}\text { capsule } \\
\text { type }\end{array}$ & mecA & $\begin{array}{l}\text { Delta } \\
\text { mecR }\end{array}$ & $c c r A / B-1$ & $C c r A / B-2$ & $c c r A A / C$ & $\begin{array}{l}k d p \text { SCC } \\
\text { locus }\end{array}$ & $b l a z / R / l$ & $\operatorname{erm}(C)$ & $m s r(A)+m p h(C)$ & aacA-aphD & $\operatorname{aadD}$ \\
\hline 1 & MW2 & US & [16] & $\mathrm{t} 128$ & ST1 & III & 8 & + & + & - & + & - & - & + & - & - & - & - \\
\hline 2 & Sanger 476 & UK & [17] & t607 & ST1 & III & 8 & - & - & + & - & - & - & + & - & - & - & - \\
\hline 3 & N315 & Japan & [18] & t002 & ST5 & $\|$ & 5 & + & + & - & + & - & + & + & - & - & - & + \\
\hline 4 & Mu50 & Japan & {$[18]$} & t002 & ST5 & $\|$ & 5 & + & + & - & + & - & + & - & - & - & + & + \\
\hline 5 & 07-17048 & WA/India & {$[6,12]$} & t3387 & ST772 & $\|$ & 5 & + & - & - & - & + & - & + & - & + & + & - \\
\hline 6 & 09 V32405 & Saxony & {$[6]$} & n.a. & n.a. & ॥ & 5 & + & - & - & - & + & - & + & + & + & + & - \\
\hline 7 & 10 V3510 & Saxony/India & [6] & n.a. & n.a. & $\|$ & 5 & + & - & - & - & + & - & + & - & + & + & - \\
\hline 8 & 11ANR12420 & Saxony & - & n.a. & n.a. & $\|$ & 5 & + & - & - & - & + & - & + & - & + & + & - \\
\hline 9 & 12ANR75832 & Saxony & - & n.a. & n.a. & $\|$ & 5 & + & - & - & - & + & - & + & - & + & + & - \\
\hline 10 & $11-18844$ & WA & - & t657 & n.a. & $\|$ & 5 & + & - & - & - & + & - & + & - & + & - & - \\
\hline 11 & $11-18907$ & WA & - & t657 & n.a. & $\|$ & 5 & + & - & - & - & + & - & + & - & + & + & - \\
\hline 12 & $11-19350$ & WA & - & t4599 & n.a. & $\|$ & 5 & + & - & - & - & + & - & + & - & - & + & - \\
\hline 13 & $11-19415$ & WA & - & t657 & n.a. & $\|$ & 5 & + & - & - & - & + & - & + & - & + & + & - \\
\hline 14 & $11-19454$ & WA & - & t1075 & n.a. & ॥ & 5 & + & - & - & - & + & - & + & + & + & + & - \\
\hline 15 & $\begin{array}{l}03-16918 \\
\text { (WA-10) }\end{array}$ & WA & {$[6,19]$} & t5073 & ST573 & ॥ & 5 & + & - & - & - & + & - & + & - & - & - & - \\
\hline 16 & $11-16548$ & WA & - & n.a. & ST772 & $\|$ & 5 & + & - & - & - & + & - & + & - & + & + & - \\
\hline 17 & 05 V02622 & Saxony & - & n.a. & n.a. & $\|$ & 5 & - & - & - & - & - & - & + & - & - & - & - \\
\hline 18 & DP15 & Australia & - & n.a. & ST772 & $\|$ & 5 & - & - & - & - & - & - & + & - & + & - & - \\
\hline
\end{tabular}


Table 1 Overview on typing and microarray hybridisation data for CC1 reference strains (nr. 1 and 2 ), CC5 reference strains (nr. 3 and 4 ), the strain described herein (nr. 5), other Bengal Bay isolates (nr. 6 to 14) and other, related strains (nr. 15 to 18) (Continued)

\begin{tabular}{|c|c|c|c|c|c|c|c|c|c|c|c|c|c|c|c|c|c|c|c|}
\hline Nr. & $a p h A 3+s a t$ & $\begin{array}{l}\text { fusC } \\
\text { (Q6GD50) }\end{array}$ & $\operatorname{tet}(K)$ & tet(M) & tst1 & sea & $\begin{array}{l}\text { sea } \\
(N 315) / s e p\end{array}$ & $\mathrm{sec} / \mathrm{sel}$ & sed $/ \mathrm{j} / \mathrm{r}$ & $\begin{array}{l}\text { egc } \\
\text { (total) }\end{array}$ & seh & sek/q & $\begin{array}{l}\text { ORF } \\
\text { CM14 }\end{array}$ & lukF/S-PV & lukD/E & sak & chp & scn & $s p l A+s p l B$ \\
\hline 1 & - & - & - & - & - & + & - & + & - & - & + & + & - & + & + & + & - & + & + \\
\hline 2 & - & + & - & - & - & + & - & - & - & - & + & + & - & - & + & + & - & + & + \\
\hline 3 & - & - & - & - & + & - & + & + & - & + & - & - & - & - & + & + & + & + & + \\
\hline 4 & - & - & - & + & + & + & - & + & - & + & - & - & - & - & + & + & - & + & + \\
\hline 5 & + & - & - & - & - & + & - & + & - & + & - & - & + & + & - & - & - & + & - \\
\hline 6 & + & - & - & - & - & + & - & + & - & + & - & - & + & + & - & - & - & + & - \\
\hline 7 & + & - & - & - & - & + & - & + & - & + & - & - & + & + & - & - & - & + & - \\
\hline 8 & + & - & - & - & - & + & - & + & - & + & - & - & + & + & - & - & - & + & - \\
\hline 9 & + & - & - & - & - & + & - & + & - & + & - & - & + & + & - & - & - & + & - \\
\hline 10 & + & - & - & - & - & + & - & + & - & + & - & - & + & + & - & - & - & + & - \\
\hline 11 & + & - & - & - & - & + & - & + & - & + & - & - & + & + & - & - & - & + & - \\
\hline 12 & - & - & - & - & - & + & - & + & - & + & - & - & + & + & - & - & - & + & - \\
\hline 13 & + & - & - & - & - & + & - & + & - & + & - & - & + & + & - & - & - & + & - \\
\hline 14 & + & - & - & - & - & + & - & + & - & + & - & - & + & + & - & - & - & + & - \\
\hline 15 & - & - & - & - & - & - & - & + & - & + & - & - & + & - & - & - & - & + & - \\
\hline 16 & + & - & - & - & - & - & - & + & - & + & - & - & + & - & - & - & $(+)$ & + & - \\
\hline 17 & - & - & - & - & - & - & - & + & - & + & - & - & + & - & - & - & - & + & - \\
\hline 18 & + & - & - & - & - & + & - & + & - & + & - & - & + & + & - & - & - & + & - \\
\hline
\end{tabular}


(hypothetical protein, located next to serine protease operon) are absent in ST772, but present in other CC1 strains. In lieu of seh, the enterotoxin homologue ORF CM14 was identified in a similar position, i.e., closely downstream of the integration site of the SCCmec element. ORF CM14, absent in the related and possibly parental lineages $\mathrm{CC} 1$ and $\mathrm{CC} 5$ can be found in a number of different lineages including CC12, ST93, CC121, CC395 and $\mathrm{CC} 705$. This may indicate a small scale genomic replacement in a region close/downstream to oriC. Alternatively, ORF CM14 may have been replaced by seh in ancestors of $\mathrm{CC} 1$ or entirely deleted in $\mathrm{CC} 5$, but retained only in ST772.
Isolate 07-17048 harbours the enterotoxin A and PVL encoding sea and $l u k F / S-P V$ genes. Both genes are located on the same contig, and together with several other phage-associated genes, appear to be on a novel prophage. The phage is integrated into a gene of the putative protein A5IT17 which contains an attachment site of the PVL-carrying phage previously identified in other strains (un-truncated in the CC1 strain MSSA476, BX571857.1: SAS1429; truncated in the CC1 strain MW2-USA400, BA000033.2: MW1377/1443). All phageassociated genes identified are shown in Table 2.

Genes sea and sprFG are normally associated with haemolysin beta converting phages rather than with PVL

Table 2 Genes associated with the PVL prophage in isolate 07-17048

\begin{tabular}{|c|c|c|c|c|}
\hline Designation & Explanation & $\begin{array}{l}\text { Position in } \\
\text { contig }\end{array}$ & Length & Best match \\
\hline$t x \_l u k F-P V$ & Rho-independent terminator of lukF-PV & $89974 \ldots 90030$ & 56 & MW2-USA400, BA000033.2 [1529274:1529329:r]RC \\
\hline lukF-PV & Panton-Valentine leukocidin F & $90081 \ldots 91059$ & 978 & MW2-USA400, BA000033.2 [1529381:1530358:r]RC \\
\hline lukS-PV & Panton-Valentine leukocidin S & $91060 \ldots 91999$ & 939 & CIGC128, AHVY01000005.1 [221466:222404:r]RC \\
\hline 080065 & $\begin{array}{l}\text { Putative protein directly upstream } \\
\text { of lukS-PV - leader-peptide of lukPV }\end{array}$ & $92106 \ldots 92239$ & 133 & CIGC128, AHVY01000005.1 [222512:222644:r]RC \\
\hline tx_amidase1-phiSLT & $\begin{array}{l}\text { Rho-independent terminator of } \\
\text { bacteriophage amidase }\end{array}$ & $92327 \ldots 92383$ & 56 & TCH1516, CP000730.1 [1562363:1562418:r]RC \\
\hline amidase1-phi12 & Bacteriophage amidase & $92388 \ldots 93843$ & 1455 & MW2-USA400, BA000033.2 [1531688:1533142:r]RC \\
\hline holin 1-phil54a & Bacteriophage holin & $93853 \ldots 94156$ & 303 & MSSA476, BX571857.1 [1023464:1023766]RC \\
\hline sprFG & Small pathogenicity island RNA $F$ and $G$ & $94155 \ldots 94266$ & 211 & ED98, CP001781.1 [892742:892952:r] \\
\hline rliz8 & Listeria sRNA rli28 homolog, locus 2 & $94395 \ldots 94574$ & 179 & MW2-USA400, BA000033.2 [2051199:2051377:r]RC \\
\hline txpA-phage & Toxin involved in plasmid maintenance & $94400 \ldots 94535$ & 1662 & MW2-USA400 BA000033.2[2051171:2051305:r]RC \\
\hline sea & Enterotoxin A & $94652 \ldots 95426$ & 774 & ST772 strain 118, AJGE01000058.1 [57550:58323]RC \\
\hline minor-phiNM3 & Bacteriophage minor structural protein & $96751 \ldots 100537$ & 3786 & TCH70-ST1, ACHH02000016.1 [79909:83694]RC \\
\hline Q8SDK3-phiNM3 & Putative bacteriophagal protein & $100552 \ldots 102037$ & 1485 & ST772 strain 118, AJGE01000058.1 [50939:52423]RC \\
\hline measure1-phiNM3 & $\begin{array}{l}\text { Bacteriophage tail length tape } \\
\text { measure protein }\end{array}$ & $102033 \ldots 106578$ & 4545 & 04-02981, CP001844.2 [2051791:2056320:r]RC \\
\hline taill-CC5 & Bacteriophage major tail protein & $107488 \ldots 108133$ & 645 & N315, BA000018.3 [2024201:2024845:r]RC \\
\hline AOEWZ3 & Bacteriophage major capsid protein & $109862 \ldots 111008$ & 1146 & Mu50-VRSA, BA000017.4 [2103511:2104656:r]RC \\
\hline Q6GF91 & Putative protease & $111031 \ldots 111769$ & 738 & A9299, ACKH01000012.1 [7311:8048]RC \\
\hline portal1-phiNM3 & Bacteriophage portal protein type 1 & $111752 \ldots 112940$ & 1188 & Mu50-VRSA, BA000017.4 [2105401:2106588:r]RC \\
\hline terminase-phiNM3 & Bacteriophagal terminase & $112955 \ldots 114617$ & 1662 & Mu50-VRSA, BA000017.4 [2106604:2108265:r]RC \\
\hline rinB-phiPVL & Bacteriophage transcript activator B & $116263 \ldots 116413$ & 150 & TCH1516, CP000730.1 [2111630:2111779:r]RC \\
\hline dut-phi & Phage dUTP pyrophosphatase & $117277 \ldots 117820$ & 543 & MRSA252, BX571856.1 [2152883:2153425:r]RC \\
\hline sri & Staphylococcal replication inhibitor & $120465 \ldots 120624$ & 159 & AP009351.1 [1110173:1110331]RC \\
\hline ist $B$ & Replicative DNA helicase & $120617 \ldots 121397$ & 780 & $\begin{array}{l}\text { phage, FJ713816.1 [12631:13404]RC and 04-02981, } \\
\text { CP001844.2 [886487:887266]RC }\end{array}$ \\
\hline Q4ZAK4 & Putative bacteriophagal protein & $121406 \ldots 122177$ & 771 & 04-02981, CP001844.2 [885707:886477]RC \\
\hline ssb3-phage & Putative DNA binding protein & $123346 \ldots 123898$ & 552 & NCTC8325, CP000253.1 [2065949:2066500:r]RC \\
\hline DUF2483-phi80a & Putative bacteriophagal protein & $124707 \ldots 124929$ & 222 & H19, ACSS01000056.1 [6024:6245:r]RC \\
\hline ant-phiPV83 & Bacteriophage antirepressor & $127131 \ldots 127929$ & 798 & phage, AY508486.1 [26092:26889]RC \\
\hline repressor-var3 & Bacteriophage repressor & $128338 \ldots 129067$ & 729 & phage, AP001553.1 [2342:3070:r] \\
\hline int1-phiPVLO1 & Bacteriophage integrase & $131132 \ldots 132338$ & 1206 & ST772 strain 118, AJGE01000058.1 [20637:21842:r] \\
\hline
\end{tabular}


phages. In ST772-MRSA-V, haemolysin beta is interrupted, but there is no complete phage integrated into that gene. Only genes encoding the staphylococcal complement inhibitor $s c n$, the putative membrane protein Q6GFB6 (usually located next to sch on hlb-converting phages, e.g., in genomes of USA300 and USA400, N315, Mu50, NCTC8325, MRSA252, MSSA476) and sprD (coding for small pathogenicity island RNA D) can be found within $h l b$. A possible assembly error affecting both phage integration sites is highly unlikely. Several other ST772MRSA-V genome sequences [22,24] also show this association of $l u k F / S-P V$ with sea. Besides, rare naturally occurring variants of ST772-MRSA-V and the related (single locus variant) ST573-MRSA-V (WA MRSA-10, [19]) lack lukS/ $F-P V$ and sea while still harbouring scn. Similar constellations can also be observed in ST573/772 MSSA (Table 1). Thus it is more likely that a part of the hlb-converting phage was translocated into a PVL phage that is integrated into a different position of the staphylococcal genome.

Other genes that are associated with mobile genetic elements include enterotoxin genes sec and sel. They are localised in similar position and context as in MW2, where they are also accompanied by phage derived genes and by the gene ear encoding the enterotoxin-linked ampicillin resistance protein. For resistance genes blaZ/I/ $R$, $m s r(\mathrm{~A}), \operatorname{mph}(\mathrm{C}), a a c A-a p h D$, $a p h A 3$, sat and $a a d E$ it was not possible to unambiguously determine with the given set of contigs whether they were situated on the chromosome or on plasmids. The macrolide/clindamycin resistance gene $\operatorname{erm}(\mathrm{C})$, and $m s r(\mathrm{~A}), m p h(\mathrm{C}), a a c A-a p h D$, $a p h A 3$ and sat genes have been shown by microarray hybridisation to occur variably in ST772-MRSA-V (Table 1).

The isolate 07-17048 harbours a SCCmec V element. Its terminal sequence towards orf $X$ was also present in another ST772-MRSA-V sequence (strain 118, [22]) and appears to be unique to ST772-MRSA-V. The SCCmec V element consists of a tnpIS431-04, mvaS-SCC (a truncated 3-hydroxy-3-methylglutaryl CoA synthase), a putative protein Q5HJW6, dru (SCC-associated direct repeat units), $u g p Q$ (glycerophosphoryl diester phosphodiesterase), ydeM (a putative dehydratase), a bidirectional rho-independent terminator of mecA followed by mecA in an allelic variant identical to GQ902038 and AM990992 [25], a series of genes coding for putative proteins (Q4LAG7, Q3T2N0, Q4LAG4, Q4LAG3, Q3T2M7), a recombinase homologue "ccrAA" [26], a SCCmec type V recombinase $c c r C$, further genes encoding putative proteins (Q4LAF9, Q7A206, Q7A207, Q9KX75, A9UFT0), a bidirectional rhoindependent terminator of $h s d R$ and three genes $(h s d R$, $h s d S$, $h s d M 2$ ) of a type I restriction-modification system.

\section{Conclusion}

In conclusion, ST772-MRSA-V may have emerged from the same root or lineage as the global CC1 and CC5 strains. It has acquired a variety of virulence factors, and, compared to other CA-MRSA strains, it has an unusually high number of genes associated with antibiotic resistance. Whether it evolved in a hospital setting or acquired these genes in community cannot be decided based on a single sequence. Therefore, more epidemiological data and possibly the sequencing of a number of additional isolates are warranted in order to understand the evolution and spread of this conspicuous strain.

\section{Additional files}

Additional file 1: Full array hybridisation for isolates from this study.

Additional file 2: Raw sequences of 70 contigs of isolate 07-17048.

Additional file 3: Annotated draft genome sequence for isolate 07-17048.

\section{Competing interests}

S. Monecke, V. Baier, P. Slickers, A. Ziegler and R. Ehricht are employees of Alere Technologies. There was no external funding for this study.

\section{Authors' contributions}

SM, GC and RE wrote the manuscript; GC and SM obtained and characterised isolates; SM, RE and PS analysed the sequence data; VB, PS and AZ wrote software tools used for the study. All authors read and approved the final manuscript.

\section{Acknowledgements}

We acknowledge A. Ruppelt, B. Stieber (Dresden), A. Reissig, J. Sachtschal and E. Mueller (Jena) as well as H.L. Tan and J. Pearson (Perth) for excellent technical assistance as well as Prof. Dr. E. Jacobs (Dresden) and E. Ermantraut (Jena) for their support. We thank Geneservice Source BioScience for their efforts, A. Shore and Peter Kinnevey (Dublin) for help and information as well as C. Scott and S. Proft for proofreading the manuscript.

\section{Author details}

${ }^{1}$ Institute for Medical Microbiology and Hygiene, Technical University of Dresden, Dresden, Germany. ${ }^{2}$ Alere Technologies GmbH, Jena, Germany. ${ }^{3}$ Australian Collaborating Centre for Enterococcus and Staphylococcus Species (ACCESS) Typing and Research, Curtin University, Perth, Western Australia. ${ }^{4}$ Department of Microbiology and Infectious Diseases, PathWest Laboratory Medicine - WA, Royal Perth Hospital, Perth, Western Australia.

Received: 20 June 2013 Accepted: 17 December 2013

Published: 20 December 2013

\section{References}

1. Kaneko J, Kamio Y: Bacterial two-component and hetero-heptameric pore-forming cytolytic toxins: structures, pore-forming mechanism, and organization of the genes. Biosci Biotechnol Biochem 2004, 68(5):981-1003.

2. Boyle-Vavra S, Daum RS: Community-acquired methicillin-resistant Staphylococcus aureus: the role of Panton-Valentine leukocidin. Lab Invest 2007, 87(1):3-9.

3. Ellington MJ, Ganner M, Warner M, Cookson BD, Kearns AM: Polyclonal multiply antibiotic-resistant methicillin-resistant Staphylococcus aureus with Panton-Valentine leucocidin in England. J Antimicrob Chemother 2010, 65(1):46-50.

4. Goering RV, Shawar RM, Scangarella NE, O'Hara FP, Amrine-Madsen H, West JM, Dalessandro M, Becker JA, Walsh SL, Miller LA, et al: Molecular Epidemiology of Methicillin-Resistant and Methicillin-Susceptible Staphylococcus aureus Isolates from Global Clinical Trials. J Clin Microbio/ 2008, 46(9):2842-2847.

5. Brennan Gl, Shore AC, Corcoran S, Tecklenborg S, Coleman DC, O'Connell B. Emergence of Hospital- and Community-Associated Panton-Valentine Leukocidin-Positive Methicillin-Resistant Staphylococcus aureus Genotype 
ST772-MRSA-V in Ireland and Detailed Investigation of an ST772-MRSA-V Cluster in a Neonatal Intensive Care Unit. J Clin Microbio/ 2012, 50(3):841-847.

6. Monecke S, Coombs G, Shore AC, Coleman DC, Akpaka P, Borg M, Chow H, Ip M, Jatzwauk L, Jonas D, et al: A Field Guide to Pandemic, Epidemic and Sporadic Clones of Methicillin-Resistant Staphylococcus aureus. PLoS One 2011, 6(4):e17936.

7. Sanchini A, Campanile F, Monaco M, Cafiso V, Rasigade JP, Laurent F, Etienne J, Stefani S, Pantosti A: DNA microarray-based characterisation of Panton-Valentine leukocidin-positive community-acquired methicillinresistant Staphylococcus aureus from Italy. Eur J Clin Microbiol Infect Dis 2011, 30(11):1399-1408.

8. Aschbacher R, Pichon B, Spoladore G, Pagani E, Innocenti P, Moroder L, Ganner M, Hill R, Pike R, Ganthaler O, et al: High clonal heterogeneity of Panton-Valentine leukocidin-positive meticillin-resistant Staphylococcus aureus strains from skin and soft-tissue infections in the Province of Bolzano, Northern Italy. Int J Antimicrob Agents 2012, 39(6):522-525.

9. Weber S, Ehricht R, Slickers P, Abdel-Wareth L, Donnelly G, Pitout M, Monecke S: Genetic fingerprinting of MRSA from Abu Dhabi. In ECCMID: 2010; Vienna. ; 2010.

10. Monecke S, Skakni L, Hasan R, Ruppelt A, Ghazal SS, Hakawi A, Slickers P, Ehricht R: Characterisation of MRSA strains isolated from patients in a hospital in Riyadh, Kingdom of Saudi Arabia. BMC Microbiol 2012, 12(1):146.

11. Neela V, Ehsanollah GR, Zamberi S, Van Belkum A, Mariana NS: Prevalence of Panton-Valentine leukocidin genes among carriage and invasive Staphylococcus aureus isolates in Malaysia. Int J Infect Dis 2009, 13(3):e131-e132.

12. Coombs GW, Monecke S, Pearson JC, Tan HL, Chew YK, Wilson L, Ehricht R, O'Brien FG, Christiansen KJ: Evolution and diversity of communityassociated methicillin-resistant Staphylococcus aureus in a geographical region. BMC Microbiol 2011, 11:215.

13. Williamson DA, Roberts SA, Ritchie SR, Coombs GW, Fraser JD, Heffernan H: Clinical and molecular epidemiology of methicillin-resistant Staphylococcus aureus in New Zealand: rapid emergence of sequence type 5 (ST5)-SCCmecIV as the dominant community-associated MRSA clone. PLoS One 2013, 8(4):e62020.

14. Dsouza N, Rodrigues C, Mehta A: Molecular characterization of Methicillin resistant Staphylococcus aureus (MRSA) with emergence of epidemic clones ST 22 and ST 772, in Mumbai, India. J Clin Microbiol 2010, 48(5):1806-1811.

15. Shambat S, Nadig S, Prabhakara S, Bes M, Etienne J, Arakere G: Clonal complexes and virulence factors of Staphylococcus aureus from several cities in India. BMC Microbiol 2012, 12(1):64

16. Baba T, Takeuchi F, Kuroda M, Yuzawa H, Aoki K, Oguchi A, Nagai Y, Iwama $\mathrm{N}$, Asano K, Naimi T, et al: Genome and virulence determinants of high virulence community-acquired MRSA. Lancet 2002, 359(9320):1819-1827.

17. Holden MTG, Feil EJ, Lindsay JA, Peacock SJ, Day NPJ, Enright MC, Foster TJ, Moore CE, Hurst L, Atkin R, et al: Complete genomes of two clinical Staphylococcus aureus strains: Evidence for the rapid evolution of virulence and drug resistance. Proc Natl Acad Sci U S A 2004, 101(26):9786-9791

18. Kuroda M, Ohta T, Uchiyama I, Baba T, Yuzawa H, Kobayashi I, Cui L, Oguchi A, Aoki K, Nagai Y, et al: Whole genome sequencing of meticillin-resistant Staphylococcus aureus. Lancet 2001, 357(9264):1225-1240.

19. Nimmo GR, Coombs GW: Community-associated methicillin-resistant Staphylococcus aureus (MRSA) in Australia. Int J Antimicrob Agents 2008 31(5):401-410

20. Altschul SF, Gish W, Miller W, Myers EW, Lipman DJ: Basic local alignment search tool. J Mol Biol 1990, 215(3):403-410.

21. Harmsen D, Claus H, Witte W, Rothganger J, Claus H, Turnwald D, Vogel U: Typing of Methicillin-Resistant Staphylococcus aureus in a University Hospital Setting by Using Novel Software for spa Repeat Determination and Database Management. J Clin Microbiol 2003, 41(12):5442-5448.

22. Prabhakara S, Khedkar S, Loganathan RM, Chandana S, Gowda M, Arakere G, Seshasayee ASN: Draft Genome Sequence of Staphylococcus aureus 118 (ST772), a Major Disease Clone from India. J Bacteriol 2012. 194(14):3727-3728

23. Robinson DA, Enright MC: Evolution of Staphylococcus aureus by Large Chromosomal Replacements. J Bacterio/ 2004, 186(4):1060-1064.

24. Prabhakara S, Khedkar S, Shambat SM, Srinivasan R, Basu A, Norrby-Teglund A, Seshasayee ASN, Arakere G: Genome Sequencing Unveils a Novel Sea
Enterotoxin-Carrying PVL Phage in Staphylococcus aureus ST772 from India. PLoS One 2013, 8(3):e60013.

25. Monecke S, Muller E, Schwarz S, Hotzel H, Ehricht R: Rapid microarray based identification of different mecA alleles in Staphylococci. Antimicrob Agents Chemother 2012, 56(11):5547-5554

26. Coombs GW, Monecke S, Ehricht R, Slickers P, Pearson JC, Tan HL, Christiansen KJ, O'Brien FG: Differentiation of CC59 community-associated methicillin-resistant Staphylococcus aureus in Western Australia. Antimicrob Agents Chemother 2010, 54(5):1914-1921.

\section{doi:10.1186/1756-0500-6-548}

Cite this article as: Monecke et al:: Genome sequencing and molecular characterisation of Staphylococcus aureus ST772-MRSA-V, "Bengal Bay Clone". BMC Research Notes 2013 6:548.

\section{Submit your next manuscript to BioMed Central and take full advantage of:}

- Convenient online submission

- Thorough peer review

- No space constraints or color figure charges

- Immediate publication on acceptance

- Inclusion in PubMed, CAS, Scopus and Google Scholar

- Research which is freely available for redistribution

Submit your manuscript at www.biomedcentral.com/submit
C) Biomed Central 